\title{
Depression, falls, and osteoporotic fractures
}

\author{
J. Zhou ${ }^{1} \cdot$ Y. Xue $^{1}$
}

Received: 25 December 2019 / Accepted: 12 February 2020 / Published online: 13 March 2020

(C) International Osteoporosis Foundation and National Osteoporosis Foundation 2020

\section{Dear Editor,}

We read the article by Afrin et al. with great interest [1]. In their study, the authors found that for postmenopausal women, falls in the previous 12 months were associated with fracture in the following 5 years through logistic regression models. They said the models were adjusted for baseline age, body mass index, dairy calcium intake, number of prescribed medications, number of chronic health disorders, current smoking, alcohol use, leisure physical activity, restricted mobility, and use of estrogen hormone therapy. However, in our opinion, the data of depression should be considered in the study.

Depression is a global public health concern [2]. Multiple studies have proved that depression was a risk factor for osteoporotic fractures [3-5]. In our previous study, we found that for postmenopausal women with osteoporosis, depression was associated with a higher risk of thoracolumbar fracture, with more fracture pain and lower quality of life in the 2 months following fracture [5]. Furthermore, a recent meta-analysis indicated that depression was significantly related to an increased risk of osteoporotic fracture and bone loss [6].

Falls are common in the elderly and a positive correlation between depression and falls was found in a few studies [7, 8]. Hoffman et al. found that among community-dwelling older adults, depression was associated with subsequent falls, but falls were not associated with later depression [7]. In a metaanalysis, the authors demonstrated that depression was a significant predictor of falls $(\mathrm{OR}=1.46)$ [9]. Moreover, the Hendrich II Fall Risk Model is a widely used fall risk assessment tool, which is intended for the nurse at the point of care to predict patients' risk of falls [10]. In this model, depression is one of the eight risk factors.

Hence, given the sophisticated correlation among depression, falls, and osteoporotic fractures, it is necessary to take account of the data of depression in the adjusted models.

Y. Xue

xueyuanzyy@163.com

1 Department of Orthopaedic Surgery, Tianjin Medical University General Hospital, Heping District, Tianjin 300052, China
Funding information National Natural Science Foundation of China (Grant No 81871124) fund was received in support of this work.

\section{Compliance with ethical standards}

Conflict of interest None.

\section{References}

1. Afrin N, Sund R, Honkanen R, Koivumaa-Honkanen H, Rikkonen T, Williams L, Kröger H (2019) A fall in the previous 12 months predicts fracture in the subsequent 5 years in postmenopausal women. Osteoporos Int:1-9. https://doi.org/10.1007/s00198-019-05255-5

2. Malhi GS, Mann JJ (2018) Depression. Lancet 392(10161):22992312

3. Tolea MI, Black SA, Carter-Pokras OD, Kling MA (2007) Depressive symptoms as a risk factor for osteoporosis and fractures in older Mexican American women. Osteoporos Int 18(3):315-322

4. Williams LJ, Pasco JA, Jackson H, Kiropoulos L, Stuart AL, Jacka FN, Berk M (2016) Depression as a risk factor for fracture in women: a 10 year longitudinal study. J Affect Disord 192:34 40. https:// doi.org/10.1016/j.jad.2015.11.048

5. Zong Y, Tang Y, Xue Y, Ding H, Li Z, He D, Zhao Y, Wang P (2016) Depression is associated with increased incidence of osteoporotic thoracolumbar fracture in postmenopausal women: a prospective study. Eur Spine J 25(11):3418-3423

6. Wu Q, Liu B, Tonmoy S (2018) Depression and risk of fracture and bone loss: an updated meta-analysis of prospective studies. Osteoporos Int 29(6):1303-1312. https://doi.org/10.1007/s00198-018-4420-1

7. Hoffman GJ, Hays RD, Wallace SP, Shapiro MF, Ettner SL (2017) Depressive symptomatology and fall risk among communitydwelling older adults. Soc Sci Med 178:206-213

8. Eggermont LHP, Penninx BWJH, Jones RN, Leveille SG (2012) Depressive symptoms, chronic pain, and falls in older communitydwelling adults: the MOBILIZE Boston Study. J Am Geriatr Soc 60(2):230-237. https://doi.org/10.1111/j.1532-5415.2011.03829.x

9. Kvelde T, McVeigh C, Toson B, Greenaway M, Lord SR, Delbaere K, Close JCT (2013) Depressive symptomatology as a risk factor for falls in older people: systematic review and meta-analysis. J Am Geriatr Soc 61(5):694-706. https://doi.org/10.1111/jgs.12209

10. Hendrich AL, Bender PS, Nyhuis A (2003) Validation of the Hendrich II fall risk model: a large concurrent case/control study of hospitalized patients. Appl Nurs Res 16(1):9-21

Publisher's note Springer Nature remains neutral with regard to jurisdictional claims in published maps and institutional affiliations. 